\title{
Emergent versus delayed lithotripsy for obstructing ureteral stones: a cumulative analysis of comparative studies
}

\author{
Davide Arcaniolo $^{1} \cdot$ Marco De Sio $^{1} \cdot$ Jens Rassweiler $^{2} \cdot$ Jilian Nicholas $^{8}$. \\ Estevão Lima $^{3}$ - Giuseppe Carrieri ${ }^{4} \cdot$ Evangelos Liatsikos $^{5}$ - Vincenzo Mirone ${ }^{6}$. \\ Manoj Monga $^{7} \cdot$ Riccardo Autorino $^{1,8}{ }_{(\text {i) }}$
}

Received: 16 November 2016 / Accepted: 22 January 2017

(C) Springer-Verlag Berlin Heidelberg 2017

\begin{abstract}
Objective To analyze the current evidence on the use of ureteroscopy (URS) and extracorporeal shock wave lithotripsy (ESWL) for the management of obstructing ureteral stones in emergent setting.

Methods A systematic literature review was performed up to June 2016 using Pubmed and Ovid databases to identify pertinent studies. The PRISMA criteria were followed for article selection. Separate searches were done using a combinations of several search terms: "laser lithotripsy", "ureteroscopy", "extracorporeal shock wave lithotripsy", "ESWL", "rapid", "immediate", "early", "delayed", "late", "ureteral stones", "kidney stones", "renal stones". Only titles related to emergent/rapid/immediate/early (as viably defined in each study) versus delayed/late treatment of ureteral stones with either URS and/or ESWL were considered for screening. Demographics and operative outcomes were compared between emergent and delayed lithotripsy.
\end{abstract}

Riccardo Autorino

ricautor@gmail.com

Urology Unit, Second University of Naples, Naples, Italy

2 Department of Urology, SLK-Kliniken Heilbronn, Heilbronn, Germany

3 Life and Health Sciences Research Institute, University of Minho, Braga, Portugal

4 Department of Urology, University of Foggia, Foggia, Italy

5 Department of Urology, University of Patras, Patras, Greece

6 Department of Urology, Federico II University, Naples, Italy

7 Glickman Urological Kidney Institute, Cleveland Clinic, Cleveland, USA

8 University Hospitals Urology Institute, Case Western Reserve University, 27100 Chardon Rd, Richmond Heights, OH 44143, USA
RevMan review manager software was used to perform data analysis.

Results Four studies comparing emergent $(n=526)$ versus delayed $(n=987)$ URS and six studies comparing emergent $(n=356)$ versus delayed $(n=355)$ SWL were included in the analysis. Emergent URS did not show any significant difference in terms of stone-free rate (91.2 versus $90.9 \%$; OR 1.04; CI $0.71,1.52 ; p=0.84)$, complication rate $(8.7 \%$ for emergent versus $11.5 \%$ for delayed; OR 0.94; CI 0.65 , $1.36 ; p=0.74)$ and need for auxiliary procedures (OR 0.85 ; CI $0.42,1.7 ; p=0.85$ ) when compared to delayed URS. Emergent ESWL was associated with a higher likelihood of stone free status (OR 2.2; CI 1.55, 3.17; $p<0.001)$ and a lower likelihood of need for auxiliary maneuvers (OR 0.49 ; CI $0.33,0.72 ; p<0.001)$ than the delayed procedure. No differences in complication rates were noticed between the emergent and delayed ESWL ( $p=0.37)$.

Conclusions Emergent lithotripsy, either ureteroscopic or extracorporeal, can be offered as an effective and safe treatment for patients with symptomatic ureteral stone. If amenable to ESWL, based on stone and patient characteristics, an emergent approach should be strongly considered. Ureteroscopy in the emergent setting is mostly reserved for distally located stones. The implementation of these therapeutic approaches is likely to be dictated by their availability.

Keywords Emergency - Shock wave lithotripsy ·

Ureteroscopy $\cdot$ Ureteral stone

\section{Introduction}

Ureteral stones represent one of the most prevalent urologic disorders, and they can often cause ureteral obstruction leading to renal colic [1]. The aim of emergency 
treatment in patients with acute renal colic is to provide symptomatic relief, unless there are indications for immediate intervention, such as renal function impairment, and signs of urinary tract infections or sepsis [2]. Traditionally, when conservative drug therapy is not able to manage pain, the placement of a ureteral stent or nephrostomy is mandated, with no clear advantage of one over the other. Then, management of the ureteral stone is usually delayed, with options including medical expulsive therapy, extracorporeal shockwave lithotripsy (ESWL), and ureteroscopy (URS) [3]. Stone size, degree of obstruction, technical facilities, surgeon and patient preference, comorbidities and possible complications are factors that should be considered in the treatment choice [4]. URS for ureteral stones seems to be associated with a greater stone free rate and less need for ancillary adjunctive procedures, but higher complication rates and longer hospital stay when compared to ESWL [5].

Recently, both ESWL and URS have been proposed for emergent treatment of ureteral stones, as they can provide both stone disintegration and relief from obstruction in a single stage. Such early intervention may decrease the cost of care, anesthesia risk, duration of stone-related morbidity and symptoms, and ultimately translate into improved outcomes. In addition, evidence suggests that delayed relief of ureteral obstruction can translate into long-term development of renal damage [6].

Urgent ESWL was first suggested by Joshi et al. who found this to be superior to insertion of a double $\mathrm{J}$ stent or nephrostomy tube [7]. Since then, few other series have been published, and a cumulative analysis of over 500 cases reported in 2012 confirmed that immediate SWL for a stone-induced acute renal colic results to be a safe treatment with a high success rate [8]. Improvements in endoscopic technologies and techniques have facilitated ureteroscopic management of stones over the past decade [9]. Osorio et al. first reported a series of emergent URS for obstructive ureteral stones [10], and a cumulative analysis of over 600 cases confirmed that the procedure is safe and effective [11].

Nevertheless, the role of emergency procedures for ureteral stones treatment remains to be defined, and definitive recommendations and guidelines regarding their implementation are lacking. A recent retrospective analysis carried out on a wide database including more than 10,000 patients presenting with renal colic clearly demonstrated that early treatment is associated with a reduced mortality $(0.16$ versus $0.47 \% ; p=0.002)$ when compared to delayed intervention [12].

The aim of this study was to systematically analyze the available evidence regarding the use of ESWL and URS as first line therapy for ureteral stones in the emergency setting.

\section{Materials and methods}

\section{Search strategy}

A systematic literature review was performed up to June 2016 using multiple search engines (PubMed, Ovid, and Scopus) to identify studies examining the outcomes of emergent versus delayed treatment-with either ESWL or URS — of obstructing ureteral stones.

Separate searches were done by two authors using both diagnosis (ureteral stones, kidney stones, renal stones) and intervention terms (laser lithotripsy, ureteroscopy, extracorporeal shock wave lithotripsy, ESWL, rapid, immediate, early, delayed, late). In case of disagreement, discrepancies were resolved by discussion with the senior author.

\section{Inclusion criteria and study eligibility}

Preferred Reporting Items for Systematic Reviews and Meta-analysis (PRISMA) criteria were used for article selection (http://www.prisma-statement.org) (Fig.1). Only titles related to emergent/rapid/immediate/early (as viably defined in each study) versus delayed/late treatment of ureteral stones with either URS and/or ESWL were considered for further screening. Searches excluded non-comparative (single arm) studies, publications on pediatric population, and articles not written in English. Studies not having primary data (i.e. reviews, commentaries, letters) were also excluded but examined to ensure relevant citations had been included. References of included studies were manually reviewed to identify additional studies of interest.

\section{Assessment of study quality}

Level of evidence was rated for each study according to recommendation by the Oxford Center for Evidence-Based Medicine (http://www.cebm.net). The quality of the study was determined by the Newcastle-Ottawa Scale (NOS) for nonrandomized controlled trials [13], and the Jadad scale for randomized control trials (RCTs) [14].

\section{Data analysis}

Two separate meta-analyses were performed: one on studies with ESWL (emergent versus delayed) as modality of treatment, and the other on studies with URS (emergent versus delayed) as modality of treatment.

Extracted data included: method of treatment (ESWL or URS); stone characteristics (diameter in $\mathrm{mm}$; location); outcomes (stone free rate, complication rate, auxiliary procedures).

For continuous outcomes, the weighted mean difference (WMD) was estimated. For binary variables, 


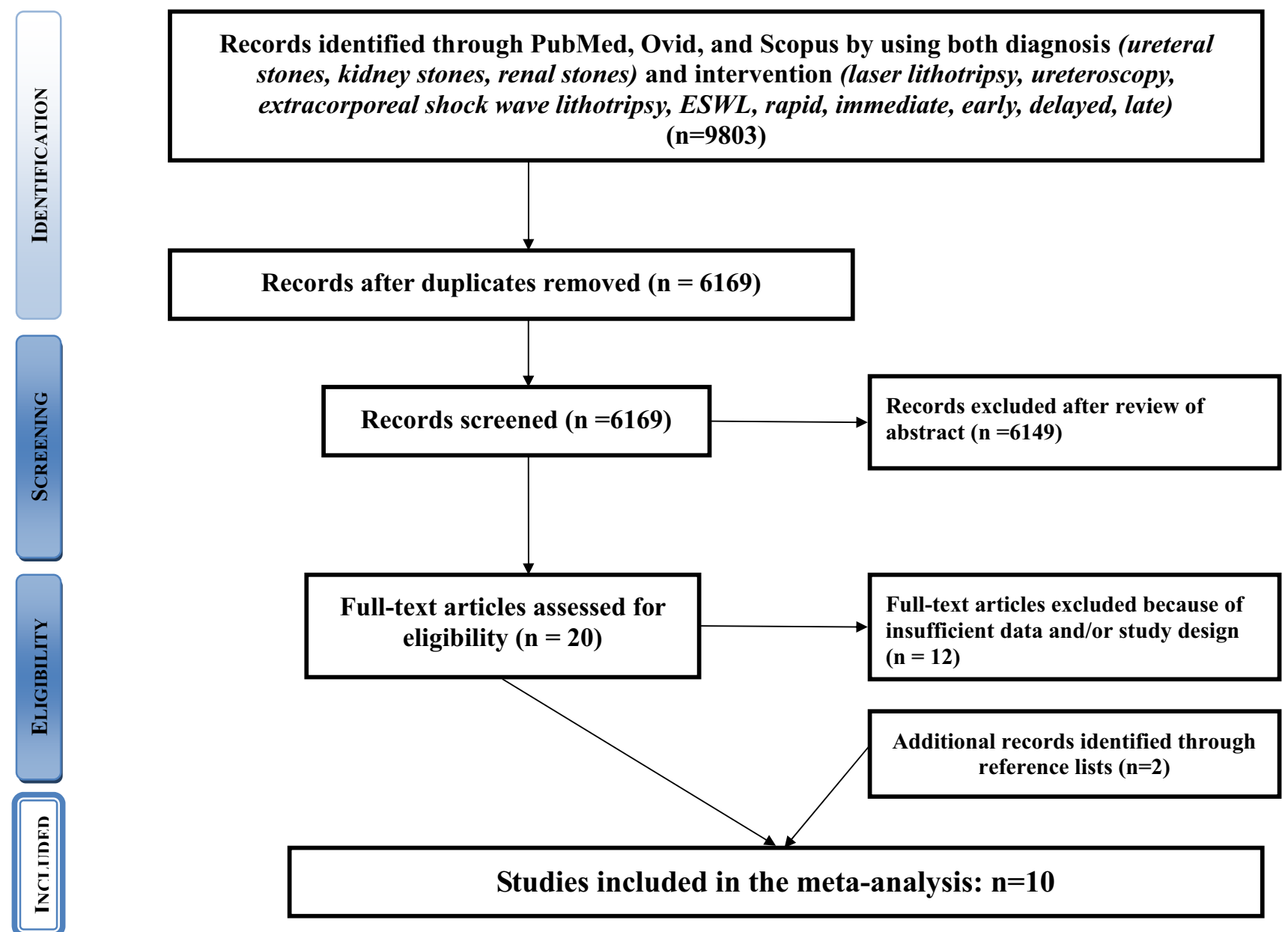

Fig. 1 PRISMA flow diagram detailing search strategy and identification of studies used in data synthesis

Odds ratio (OR) was calculated with reporting of $95 \%$ confidence intervals (CIs). As only means and standard deviations are permitted for the computational portion of meta-analyses, for those studies reporting medians and ranges, a validated mathematical model was used to convert medians (ranges) to means (standard deviations) [15].

Pooled estimates were calculated with the fixed-effect model, if no significant heterogeneity was identified; alternatively, the random-effect model was used when significant heterogeneity was detected. Statistical heterogeneity was defined based on Cochrane $\mathrm{Q} p$ value or $I^{2}$ statistics. To evaluate publication bias, Egger linear regression and funnel plots were examined. All statistical analyses were performed using Review manager software was used to performed data analyses (RevMan v.5.3).

\section{Results}

Overall, ten studies published between 2005 and 2014 were deemed eligible and included in the analysis. In four studies ( 1 prospective randomized controlled and 3 retrospective case-control studies), emergent URS $(n=526)$ was compared to delayed URS $(n=987)$. The definition of emergency varied among the studies from 12 to $48 \mathrm{~h}$ from admission to the emergency room. Stone-free status was defined on postoperative imaging (KUB in 3 studies and CT scan in one), which was done at 1 month in most studies (Table 1) [16-19]. In six studies (4 prospective randomized controlled and 2 retrospective case-control studies), emergent ESWL $(n=356)$ was compared to delayed ESWL $(n=355)$. The definition of emergency varied among the studies from 6 to $72 \mathrm{~h}$ from admission to the emergency room. Stone-free status was defined on postoperative imaging (KUB in 3 studies and CT scan in 3), which was done 


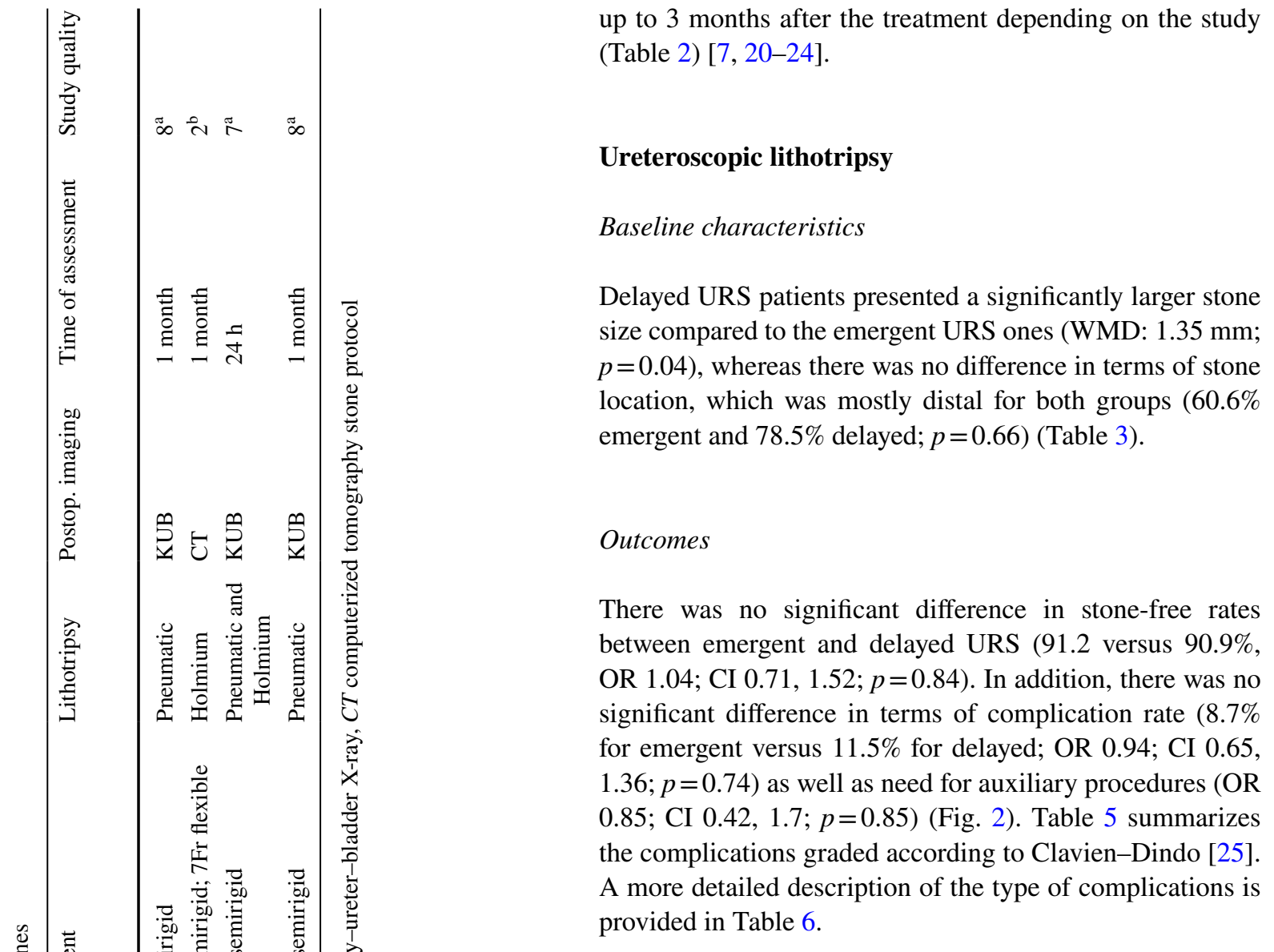

up to 3 months after the treatment depending on the study (Table 2) [7, 20-24].

\section{Ureteroscopic lithotripsy}

\section{Baseline characteristics}

Delayed URS patients presented a significantly larger stone size compared to the emergent URS ones (WMD: $1.35 \mathrm{~mm}$; $p=0.04$ ), whereas there was no difference in terms of stone location, which was mostly distal for both groups $(60.6 \%$ emergent and $78.5 \%$ delayed; $p=0.66$ ) (Table 3 ).

\section{ESWL}

\section{Baseline characteristics}

With regards to the ESWL, there was no difference between treatment groups for stone size (WMD $0.04 \mathrm{~mm} ; p=0.92$ ), whereas the delayed ESWL group presented a significantly lower proportion of distally located stone (20 versus $30.9 \%$, $p<0.001$ ) (Table 4).

\section{Outcomes}

Likelihood of stone-free status after treatment was found to be higher in the emergent ESWL group (OR 2.2; CI $1.55,3.17 ; p<0.001$ ), which also presented lower odds of need for auxiliary procedures (OR 0.49 ; CI $0.33,0.72$; $p<0.001)$. On the other hand, there was no difference in terms of risk of complications between the emergent and delayed ESWL (OR 0.79; CI 0.47, 1.32; $p=0.37$ ) (Fig. 3). Table 5 summarizes the complications graded according to Clavien-Dindo [25]. A more detailed description of the type of complications is provided in Table 6. 
Table 2 Studies comparing emergent versus delayed ESWL for ureteral stones

\begin{tabular}{|c|c|c|c|c|c|c|c|c|c|}
\hline \multirow[t]{2}{*}{ References } & \multirow[t]{2}{*}{ Study design } & \multirow[t]{2}{*}{ LoE } & \multicolumn{2}{|c|}{$\mathrm{N}$ of cases } & & \multirow[t]{2}{*}{ Lithotripsy device } & \multirow[t]{2}{*}{ Postop. imaging } & \multirow{2}{*}{$\begin{array}{l}\text { Time of assess- } \\
\text { ment }\end{array}$} & \multirow[t]{2}{*}{ Study quality } \\
\hline & & & Emerg & Delay & & & & & \\
\hline Joshi [7] & Case control & $3 b$ & 16 & 40 & Upon admission & Siemens Lithostar & KUB & After ESWL & $8^{\mathrm{a}}$ \\
\hline Kravchick [20] & RCT & $2 b$ & 25 & 28 & $48-72 \mathrm{~h}$ & Econolith & KUB & 1 month & $3^{\mathrm{b}}$ \\
\hline Tombal [21] & RCT & $1 b$ & 50 & 50 & $6 \mathrm{~h}$ & $\begin{array}{l}\text { Definition of } \\
\text { "emergency" } \\
\text { Siemens Lithostar }\end{array}$ & KUB & $24-48 \mathrm{~h}$ & $2^{\mathrm{b}}$ \\
\hline Kumar [22] & RCT & $1 b$ & 80 & 80 & $48 \mathrm{~h}$ & $\begin{array}{l}\text { Dornier Alpha } \\
\text { compact }\end{array}$ & CT & 3 months & $3^{\mathrm{b}}$ \\
\hline Uguz [23] & RCT & $1 b$ & 32 & 31 & $24 \mathrm{~h}$ & $\begin{array}{l}\text { Dornier Alpha } \\
\text { compact }\end{array}$ & $\mathrm{CT}$ & $72 \mathrm{~h}$ & $2^{\mathrm{b}}$ \\
\hline Choi [24] & Case control & $3 b$ & 153 & 126 & $48 \mathrm{~h}$ & $\begin{array}{l}\text { Dornier Compact } \\
\text { Delta }\end{array}$ & KUB/CT & 1 month & $7^{\mathrm{a}}$ \\
\hline
\end{tabular}

$R C T$ randomized clinical trial, $L o E$ level of evidence according to Oxford CEBM, Eme emergency, Del delayed, KUB kidney-ureter-bladder $\mathrm{X}$-ray, $C T$ computerized tomography stone protocol

${ }^{a}$ Newcastle Ottawa scale

bJadad scale

Table 3 Studies comparing emergent versus delayed ureteroscopic lithotripys for ureteral stones: patients and stone characteristics

\begin{tabular}{|c|c|c|c|c|c|c|c|c|c|c|}
\hline \multirow[t]{2}{*}{ References } & \multicolumn{2}{|c|}{ No. of cases } & \multicolumn{2}{|c|}{ Gender, M/F } & \multicolumn{2}{|c|}{ Age, years, mean (SD) } & \multicolumn{2}{|c|}{$\begin{array}{l}\text { Stone size, mm, mean } \\
\text { (SD) }\end{array}$} & \multicolumn{2}{|c|}{$\begin{array}{l}\text { Stone location, prox } / \mathrm{mid} / \\
\text { distal }\end{array}$} \\
\hline & Emerg & Delayed & Emerg & Delayed & Emerg & Delayed & Emerg & Delayed & Emerg & Delayed \\
\hline Youn [16] & 67 & 159 & $39 / 28$ & $89 / 70$ & $47.8(11.5)$ & $51.2(13.8)$ & $2.4(1.6)$ & $4.1(2.6)$ & $8 / 4 / 55$ & $36 / 29 / 94$ \\
\hline Guercio [17] & 139 & 100 & $163 / 81$ & & $52.7(12.5)$ & $50(10.3)$ & $8(2.1)$ & $8(2.1)$ & $13 / 30 / 68$ & $20 / 25 / 40$ \\
\hline Sarica [18] & 76 & 69 & $45 / 31$ & $51 / 18$ & $34(8.1)$ & $44(15.3)$ & $8.3(2)$ & $11.8(4)$ & $29 / \mathrm{nr} / 47$ & $18 / \mathrm{nr} / 51$ \\
\hline Matani [19] & 244 & 659 & $184 / 60$ & $508 / 151$ & $45.6(13.2)$ & $43.4(15.3)$ & $9.2(4.4)$ & $9.6(5.3)$ & $49 / 46 / 149$ & $147 / 79 / 433$ \\
\hline
\end{tabular}

$M$ male, $F$ female, $n r$ not reported, Emerg emergent ureteroscopic lithotripsy, Delayed delayed ureteroscopic lithotripsy, $S D$ standard deviation

\section{Discussion}

The rationale for an early therapy in patients affected by ureteral stones accompanied by colic is ureteral edema gradually develops after $24-48 \mathrm{~h}$, progressing with time, and ultimately impairing the stone clearance [26, 27]. Cummings et al. demonstrated using an artificial neural network that the duration of symptoms before treatment and hydronephrosis grade represent the most important factors in predicting the passage of ureteral stones [28]. This argument holds especially true for ESWL treatment as the onset of edema determines inhibition of the expansion chamber formation and removal of the fluid layer between the stone and the tissue, reducing fragmentation rates of shockwaves [29]. According to Kumar et al., the days needed for stone clearance, the retreatment rate and the requirement of auxiliary procedures are significantly higher when treatment is performed beyond $48 \mathrm{~h}$ from pain onset and the more time passes, the greater is this increase [22].

Herein, we report the first meta-analysis of studies comparing emergent versus delayed lithotripsy for obstructing ureteral stones, including four studies on URS (including one randomized controlled trial), and six studies on ESWL (including four randomized controlled trials). The present analysis of a large pooled sample (over 1600 URS cases, and over 700 ESWL cases) can contribute to the ongoing debate, ultimately paving the way for further research on this topic, and also it can provide key information for contemporary evidence-based patient counseling. In this respect, a recent analysis of the Healthcare Cost and Utilization Project State Inpatient Database for Florida and California from 2007 to 2011 on over 10,000 patients admitted for obstructing nephrolithiasis revealed that early intervention occurred in $65 \%$ of cases, and this was associated with a decrease in mortality $(0.16 \%)$, compared to delayed intervention $(0.47 \%$, $p=0.002)$ [12].

Our findings confirm that URS is an effective and safe procedure when performed in emergency setting (variably defined as ureteroscopy performed $12-48 \mathrm{~h}$ since admission to the emergency department), without significant differences in terms of stone-free rate, complication rates, and 


\section{(a) STONE FREE RATE}

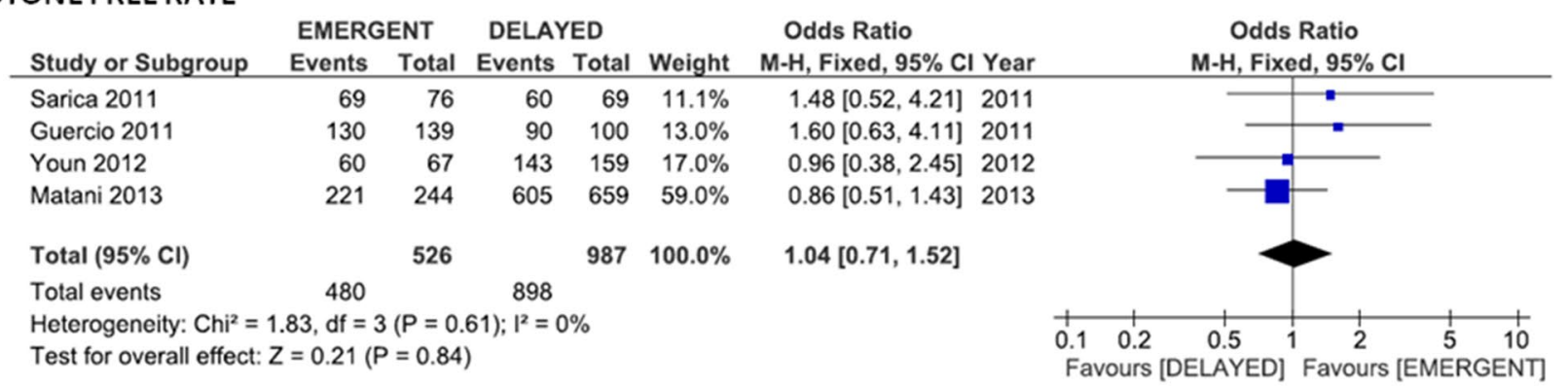

\section{(B) COMPLICATION RATE}

\begin{tabular}{|c|c|c|c|c|c|c|c|c|c|}
\hline \multirow[b]{2}{*}{ Study or Subgroup } & \multicolumn{2}{|c|}{ EMERGENT } & \multicolumn{2}{|c|}{ DELAYED } & \multicolumn{3}{|c|}{ Odds Ratio } & \multirow{2}{*}{\multicolumn{2}{|c|}{$\begin{array}{c}\text { Odds Ratio } \\
\text { M-H, Fixed, } 95 \% \mathrm{Cl}\end{array}$}} \\
\hline & Events & Total & Events & Total & Weight & M-H, Fixed, $95 \% \mathrm{Cl}$ & Year & & \\
\hline Guercio 2011 & 2 & 139 & 2 & 100 & $4.0 \%$ & $0.72[0.10,5.17]$ & 2011 & & \\
\hline Sarica 2011 & 9 & 76 & 2 & 69 & $3.2 \%$ & $4.50[0.94,21.61]$ & 2011 & & \\
\hline Youn 2012 & 3 & 67 & 15 & 159 & $14.8 \%$ & $0.45[0.13,1.61]$ & 2012 & & \\
\hline Matani 2013 & 32 & 244 & 95 & 659 & $77.9 \%$ & $0.90[0.58,1.38]$ & 2013 & & \\
\hline Total $(95 \% \mathrm{Cl})$ & & 526 & & 987 & $100.0 \%$ & $0.94[0.65,1.36]$ & & & \\
\hline Total events & 46 & & 114 & & & & & & \\
\hline $\begin{array}{l}\text { Heterogeneity: } \mathrm{Ch}^{2} \\
\text { Test for overall effec }\end{array}$ & $\begin{array}{l}5.23, d f= \\
Z=0.33(\end{array}$ & $\begin{array}{l}3(P=C \\
P=0.7\end{array}$ & $\begin{array}{l}0.16) ; 1^{2}= \\
\text { 4) }\end{array}$ & $43 \%$ & & & & $\begin{array}{ccc}1 & 1 & 1 \\
0.1 & 0.2 & 0.5 \\
\text { Favours [EMERGENT] }\end{array}$ & $\begin{array}{cccc} & 1 & 1 & 1 \\
1 & 2 & 5 & 10 \\
\text { Favours [DELAYED] }\end{array}$ \\
\hline
\end{tabular}

\section{(C) AUXILIARY PROCEDURES}

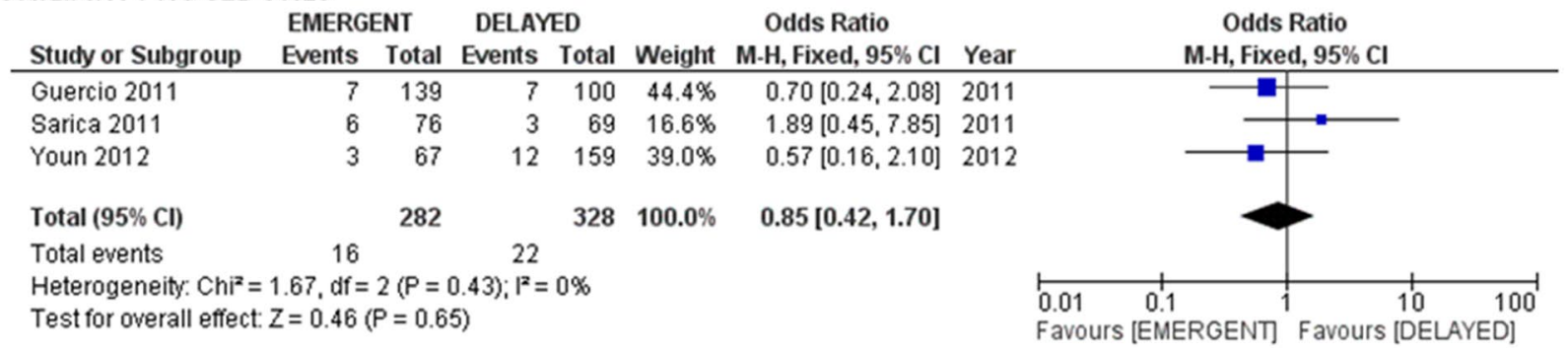

Fig. 2 Emergent versus delayed ureteroscopy for obstructing ureteral stones: forest plots for a stone-free rate; b complication rate; $\mathbf{c}$ auxiliary procedures

Table 4 Studies comparing emergent versus delayed ESWL for ureteral stones: patients and stone characteristics

\begin{tabular}{|c|c|c|c|c|c|c|c|c|c|c|}
\hline \multirow[t]{2}{*}{ References } & \multicolumn{2}{|c|}{ No. of cases } & \multicolumn{2}{|c|}{ Gender, M/F } & \multicolumn{2}{|c|}{ Age, years, mean (SD) } & \multicolumn{2}{|c|}{$\begin{array}{l}\text { Stone size, mm, mean } \\
\text { (SD) }\end{array}$} & \multicolumn{2}{|c|}{$\begin{array}{l}\text { Stone location, prox/ } \\
\mathrm{mid} / \text { distal }\end{array}$} \\
\hline & Emerg & Delayed & Emerg & Delayed & Emerg & Delayed & Emerg & Delayed & Emerg & Delayed \\
\hline Joshi [7] & 16 & 40 & $12 / 4$ & $28 / 12$ & 54.3 & 49.6 & 8.2 & 9.3 & $6 / 3 / 7$ & $31 / 4 / 5$ \\
\hline Kravchick [20] & 25 & 28 & $36 / 64$ & $44 / 56$ & $45.2(10.6)$ & $47.9(11.6)$ & $7.4(2.4)$ & $6.9(2.4)$ & $18 / \mathrm{nr} / 7$ & $25 / \mathrm{nr} / 3$ \\
\hline Tombal [21] & 50 & 50 & $40 / 10$ & $43 / 7$ & 44 & 42 & $6(2)$ & $5(2)$ & $29 / \mathrm{nr} / 21$ & $17 / \mathrm{nr} / 33$ \\
\hline Kumar [22] & 80 & 80 & $44 / 36$ & $46 / 34$ & $37.4(2)$ & $37.3(2.5)$ & $7.3(1.5)$ & $7.5(1.7)$ & $\mathrm{nr}$ & $\mathrm{nr}$ \\
\hline Uguz [23] & 32 & 31 & $25 / 7$ & $25 / 6$ & $36.7(12.7)$ & $37.6(12.8)$ & $8.1(3.1)$ & $8.8(2.9)$ & $21 / 2 / 9$ & $20 / 4 / 7$ \\
\hline Choi [24] & 153 & 126 & $108 / 45$ & $96 / 30$ & $43.6(12.9)$ & $45.1(13.1)$ & $7.6(2.5)$ & $8.3(3.1)$ & $93 / 6 / 54$ & $90 / 6 / 30$ \\
\hline
\end{tabular}

$M$ male, $F$ Female, $n r$ not reported, Emerg emergent SWL lithotripsy, Delayed delayed SWL lithotripsy, SD standard deviation

need of ancillary procedures when compared to delayed ureteroscopy.

Osorio et al. reported the first series of emergency ureteroscopy in 2007 [10]. They performed a retrospective analysis on 144 patients performed mostly (90\%) for distal stones (mean stone diameter $9 \mathrm{~mm}$ ), and they had an overall stone-free rate of $92.4 \%$. They observed that greater stonefree rate was achieved in patients with stones $<10 \mathrm{~mm}$ 


\section{(a) STONE FREE RATE}

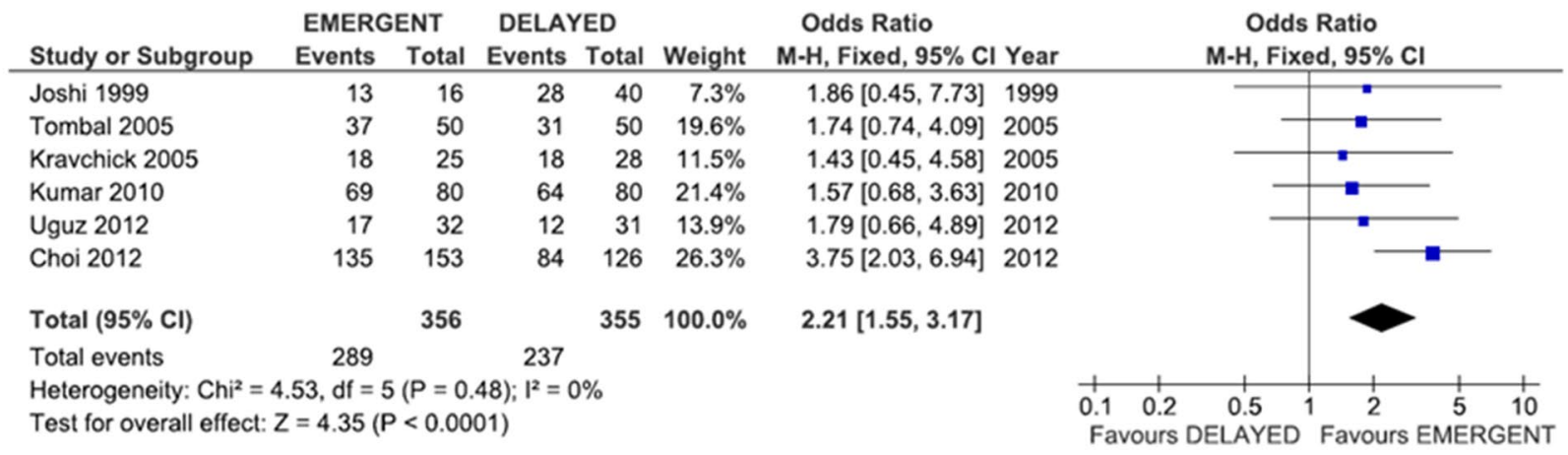

\section{(B) COMPLICATION RATE}

\begin{tabular}{|c|c|c|c|c|c|c|c|c|}
\hline \multirow[b]{2}{*}{ Study or Subgroup } & \multicolumn{2}{|c|}{ EMERGENT } & \multicolumn{2}{|c|}{ DELAYED } & \multicolumn{3}{|c|}{ Odds Ratio } & \multirow{2}{*}{$\begin{array}{c}\text { Odds Ratio } \\
\text { M-H, Fixed, } 95 \% \mathrm{Cl}\end{array}$} \\
\hline & Events & Total & Events & Total & Weight & M-H, Fixed, $95 \% \mathrm{Cl}$ & Year & \\
\hline Kumar 2010 & 36 & 80 & 44 & 80 & $74.8 \%$ & $0.67[0.36,1.25]$ & 2010 & \\
\hline Choi 2012 & 11 & 153 & 8 & 126 & $25.2 \%$ & $1.14[0.45,2.93]$ & 2012 & \\
\hline Total $(95 \% \mathrm{Cl})$ & & 233 & & 206 & $100.0 \%$ & $0.79[0.47,1.32]$ & & \\
\hline Total events & 47 & & 52 & & & & & \\
\hline $\begin{array}{l}\text { Heterogeneity. } \mathrm{Chi}^{2} \\
\text { Test for overall effec }\end{array}$ & $\begin{array}{l}0.86, d f= \\
Z=0.90\end{array}$ & $\begin{array}{l}1(P= \\
P=0.3\end{array}$ & $0.35) ; 1^{2}=$ & & & & & $\begin{array}{ccccccc} & 1 & 1 & 1 & 1 & 1 & 1 \\
0.1 & 0.2 & 0.5 & 1 & 2 & 5 & 10 \\
\text { Favours [EMERGENT] } & \text { Favours [DELAYED] }\end{array}$ \\
\hline
\end{tabular}

\section{(C) AUXILIARY PROCEDURES}

\begin{tabular}{|c|c|c|c|c|c|c|c|c|c|c|}
\hline \multirow[b]{2}{*}{ Study or Subgroup } & \multicolumn{2}{|c|}{ EMERGENT } & \multicolumn{2}{|c|}{ DELAYED } & \multicolumn{3}{|c|}{ Odds Ratio } & \multirow{2}{*}{\multicolumn{3}{|c|}{$\begin{array}{c}\text { Odds Ratio } \\
\text { M-H, Fixed, } 95 \% \mathrm{Cl}\end{array}$}} \\
\hline & Events & Total & Events & Total & Weight & M-H, Fixed, $95 \% \mathrm{Cl}$ & Year & & & \\
\hline Kravchick 2005 & 7 & 25 & 8 & 28 & $7.6 \%$ & $0.97[0.29,3.22]$ & 2005 & & & \\
\hline Tombal 2005 & 11 & 50 & 8 & 50 & $8.7 \%$ & $1.48[0.54,4.06]$ & 2005 & & & \\
\hline Kumar 2010 & 13 & 80 & 26 & 80 & $30.3 \%$ & $0.40[0.19,0.86]$ & 2010 & & & \\
\hline Uguz 2012 & 2 & 32 & 6 & 31 & $8.0 \%$ & $0.28[0.05,1.50]$ & 2012 & $\longleftarrow$ & - & \\
\hline Choi 2012 & 15 & 153 & 33 & 126 & $45.5 \%$ & $0.31[0.16,0.60]$ & 2012 & 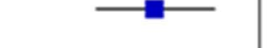 & & \\
\hline Total $(95 \% \mathrm{Cl})$ & & 340 & & 315 & $100.0 \%$ & $0.49[0.33,0.72]$ & & & & \\
\hline Total events & 48 & & 81 & & & & & & & \\
\hline $\begin{array}{l}\text { Heterogeneity: Chi } \\
\text { Test for overall effec }\end{array}$ & $\begin{array}{l}8.48, d f= \\
Z=3.58\end{array}$ & $\begin{array}{l}4(P=0 \\
P=0.00\end{array}$ & $\begin{array}{l}0.08) ; 1^{2}= \\
003)\end{array}$ & $53 \%$ & & & & $\begin{array}{ccc}0.1 & 0.2 & 0.5 \\
\text { Favours [EMERGENT] }\end{array}$ & $\frac{2}{2}$ & $\begin{array}{cc}5 & 10 \\
\text { ELLAYED] }\end{array}$ \\
\hline
\end{tabular}

Fig. 3 Emergent versus delayed ESWL: forest plots for a stone-free rate; $\mathbf{b}$ complication rate; $\mathbf{c}$ auxiliary procedures

Table 5 Complications rate according to Clavien-Dindo grading system

\begin{tabular}{llllll}
\hline Clavien grade & \multicolumn{2}{l}{ URS } & & ESWL \\
\cline { 2 - 3 } & Emergency $(n=526)$ & Delayed $(n=987)$ & & Emergency $(n=233)$ & Delayed $(n=206)$ \\
\hline I & $17(3.2 \%)$ & $35(3.5 \%)$ & & $41(17.6 \%)$ & $41(19.9 \%)$ \\
II & $12(2.3 \%)$ & $42(4.2 \%)$ & & - \\
IIIa & $15(2.8 \%)$ & $36(3.6 \%)$ & & $1(0.4 \%)$ & $1(0.5 \%)$ \\
IIIb & $2(0.4 \%)$ & $1(0.1 \%)$ & - & - \\
Graded n/a & - & - & $5(2.1 \%)$ & $10(4.8 \%)$ \\
Total & $46(8.7 \%)$ & $114(11.5 \%)$ & & $47(18 \%)$ & $52(20.4 \%)$ \\
\hline
\end{tabular}

(95.8\% versus $89 \% ; p=0.002)$ and in those presenting with stones in distal ureter (94.6 versus $71.4 \% ; p=0.004)$. The role of stone location and size as key factors in determining the success of URS was also confirmed by Youn et al. who found a higher stone-free rate when only distal ureteral stones were considered (97.6 versus $89.8 \%$ ), and fewer complications when only stones $<10 \mathrm{~mm}$ were taken into consideration (2.7 versus $7.96 \%$ ) [16]. Picozzi et al. estimated that every $1 \mathrm{~mm}$ of increased diameter over $8 \mathrm{~mm}$ determine a reduction of stone-free rate of $5 \%$ in distal ureter and $8.1 \%$ in proximal ureters [11]. Al Ghazo et al. stratified their 244 cases by stone location, and they found 
Table 6 Detailed description of complications graded according to Clavien-Dindo

\begin{tabular}{|c|c|c|c|}
\hline & Complication type (Clavien grade) & Emergency URS & Delayed URS \\
\hline \multirow[t]{2}{*}{ Youn [16] } & Mucosal Injury (I) & $3(4.5 \%)$ & $9(5.6 \%)$ \\
\hline & Haematuria (I) & - & $6(3.7 \%)$ \\
\hline \multirow[t]{3}{*}{ Guercio [17] } & Haematuria (I) & $1(0.7 \%)$ & - \\
\hline & Urinary tract infection (II) & $1(0.7 \%)$ & $1(1 \%)$ \\
\hline & Ureteral stricture (I) & - & $1(1 \%)$ \\
\hline \multirow[t]{2}{*}{ Sarica [18] } & Mucosal injury (I) & $6(7.9 \%)$ & $2(2.9 \%)$ \\
\hline & Haematuria (I) & $3(3.9 \%)$ & - \\
\hline \multirow[t]{11}{*}{ Matani [19] } & Flank pain (II) & $7(2.9 \%)$ & $26(3.9 \%)$ \\
\hline & Hematuria (I) & $4(1.6 \%)$ & $17(2.6 \%)$ \\
\hline & Urinary tract infection (II) & $4(1.6 \%)$ & $15(2.3 \%)$ \\
\hline & Ureteral injuries & & \\
\hline & Perforation & $7(2.9 \%)$ & $21(3.2 \%)$ \\
\hline & (IIIa) & 6 & 20 \\
\hline & (IIIb) & 1 & 1 \\
\hline & Avulsion (IIIb) & $1(0.4 \%)$ & - \\
\hline & False passage (IIIa) & $7(2.9 \%)$ & $15(2.3 \%)$ \\
\hline & Stricture (IIIa) & $2(0.8 \%)$ & $1(0.1 \%)$ \\
\hline & Complication type (Clavien grade) & Emergency ESWL & Delayed ESWL \\
\hline \multirow[t]{2}{*}{ Kumar [22] } & Steinstrasse $^{\mathrm{a}}$ & $5(6.2 \%)$ & $10(12.5 \%)$ \\
\hline & Haematuria (I) & $31(38.7 \%)$ & $34(42.5 \%)$ \\
\hline \multirow[t]{5}{*}{ Choi [24] } & Steinstrasse & & \\
\hline & Asymptomatic (I) & $2(1.3 \%)$ & $1(0.8 \%)$ \\
\hline & Symptomatic (IIIa) & $1(0.7 \%)$ & $1(0.8 \%)$ \\
\hline & Gross Haematuria (I) & $2(1.3 \%)$ & $1(0.8 \%)$ \\
\hline & Severe Pain (I) & $6(3.9 \%)$ & $5(4.0 \%)$ \\
\hline
\end{tabular}

${ }^{\mathrm{a}}$ Clavien grading not possible due to lack of data in the study

higher stone-free rates for mid (95.8\%) and distal ureter (96.6\%) compared to distal (69.4\%) [30]. Conversely, in the only randomized trial comparing emergent versus delayed URS, Guercio et al. found that neither stone size nor location had any impact on stone-free rate [17]. This finding could be explained by the fact that this was the only group to use a flexible scope (besides the semirigid one), and therefore one might expect that a more aggressive pursuit of residual or migrated fragments was implemented.

No significant difference in terms of complication was found in our analysis and this finding is similar to the 7.6\% complication rate reported in the cumulative analysis of 681 by Picozzi et al. [11]. An overall 5\% complication rate was reported by a recent large audit form New Zealand [31]. In the four comparative studies, we identified and included only two major complications, which were reported by Matani et al., who had one ureteral perforation and one avulsion caused by stone basket [19].

Our findings also support the concept that emergent ESWL is more effective (than delayed ESWL) in terms of stone-free rate, and it requires less ancillary maneuvers.
Notably, four of the six comparative studies we included were RCTs, which further corroborate these findings. However, these studies were of intermediate quality (Jadad score 2-3). Also for ESWL, the definition of "emergency" procedure varied among studies (anywhere from 6 to $72 \mathrm{~h}$ ). In their pioneering work, Joshi et al. pointed out that treating the stone emergently with ESWL can minimize the energy-absorbing effects derived from progressive wall changes related to stone impaction, ultimately translated into high success rate of the procedure [7]. Choi et al. pointed out that significantly better treatment outcomes in the emergent group were noticed only for patients with stone size $<10 \mathrm{~mm}$ and proximal ureteral stones [24]. In the study by Uguz et al., the stone-free rate was also significantly higher for immediate SWL only for upper ureteral stones $(p=0.019)$, regardless of the stone size [23]. In their pooled analysis of six studies (including 570 cases), Picozzi et al. did not register a difference in terms of stone-free rate between upper ureteral stones $(79 \%)$ versus mid $(78 \%)$ or distal (78\%) stones [8]. In their RCT, Kumar et al. showed no significant difference in stone-free rate between delayed 
and early ESWL ( 86.3 versus $80 \% ; p=0.31$ ), although they only included upper ureteral stones $<10 \mathrm{~mm}$. Notably, in this study, the need of auxiliary procedure and number of ESWL sessions was significantly lower when ESWL is performed within the first $48 \mathrm{~h}$ [22]. More recently, a group from UK reported another retrospective series of 97 patients with an overall success rate of $73 \%$, and they identified stone size and stone density (as determined by Hounsfield units) as factor predicting the outcomes of the emergency ESWL procedure. Others have reported the role of non-contrast CT scan to determine the attenuation values of urinary calculi before ESWL to predict treatment outcome [32]. As far as complication rates, no differences between emergent and delayed ESWL were noticed in our meta-analysis $(p=0.58)$.

Our study is not devoid of limitations. First, despite meta-analyses being a robust statistical tool, controversies exist regarding their relative role in surgical decisionmaking [33]. However, it has been argued that to minimize the biases, meta-analyses should be performed within the frame of systematic reviews [34], as it is the case of our work. Moreover, it should be pointed out that the analysis on URS outcomes was based on only one RCT, and this was of low quality; therefore, this should be taken into account when interpreting the results. Second, the variability in the definition of "emergent" procedure might account for some bias. Third, success rate of ureteroscopy, and ESWL can also depend on the technology and instrumentation used. This holds especially true for ESWL, where the implementation of more portable second, and third, and fourth generation machine has come to the place [35], and for which the results might be machine specific, and also depend on fine tuning of technical factors (focal zone, pulse rates, ramping strategies, coupling) [36]. Fourth, SFR was defined as absence of stone in 7 out of 11 studies, while in four studies fragments $\leq 3 \mathrm{~mm}$ were considered as a successful outcome. Moreover, imaging technique for defining the SF status (KUB and/or CT scan) and follow-up time (range $24 \mathrm{~h}-4$ weeks) widely varied among analyzed series. Fifth, we could not perform a sensitivity analysis based on stone location and size as stratified outcomes for these variables were not available in most of the included studies.

Last, this analysis does not allow a formal assessment of the cost-effectiveness of emergency lithotripsy. However, it can be speculated that achieving rapid decompression of the obstruction and pain relief in only one step can translate into a benefit in terms of decrease hospital stay, and reduction of readmissions in emergency room. In a large (over 5000 cases) data sample using claims data, Hollingsworth et al. found that men placed on medical expulsive therapy experienced higher repeat emergency department visits compared to those undergoing immediate endoscopic stone removal (68.8 versus $39.6 \%$, respectively, $p=0.025$ )
[37]. A more recent study from the same group suggested that patients receiving conservative therapy may actually file fewer short-term disability claims, and experience less income loss within the first 42 days [38]. However, these claims data are limited by the lack of information about stone size and location which may impact these findings and conclusions [39].

\section{Conclusions}

Current evidence suggests that emergent lithotripsy, either ureteroscopic or extracorporeal, can be offered as an effective and safe treatment if a patient presents with a symptomatic ureteral stone. If amenable to ESWL, based on stone and patient characteristics, an emergent approach should be strongly considered. Ureteroscopy in the emergent setting is mostly reserved for distally located stones. The implementation of these therapeutic approaches is likely to be dictated mostly by their availability in the emergency setting. The findings of the present cumulative analysis should be interpreted by taking into account its limitations. Further investigation in this area is desirable.

\section{Compliance with ethical standards}

Conflict of interest The authors declare that they have no conflict of interest.

\section{References}

1. Teichman JM (2004) Clinical practice acute renal colic from ureteral calculus. N Engl J Med 350:684-693

2. Türk C, Petř́k A, Sarica K et al (2016) EAU guidelines on diagnosis and conservative management of urolithiasis. Eur Urol 69(3):468-474

3. Türk C, Petřík A, Sarica K et al (2016) EAU guidelines on interventional treatment for urolithiasis. Eur Urol 69(3):475-482

4. Wright PJ, English PJ, Hungin AP, Marsden SN (2002) Managing acute renal colic across the primary-secondary care interface: a pathway of care based on evidence and consensus. BMJ 325:1408-1412

5. Cui X, Ji F, Yan H et al (2015) Comparison between extracorporeal shock wave lithotripsy and ureteroscopic lithotripsy for treating large proximal ureteral stones: a meta-analysis. Urology 85(4):748-756

6. Lucarelli G, Ditonno P, Bettocchi C et al (2013) Delayed relief of ureteral obstruction is implicated in the long-term development of renal damage and arterial hypertension in patients with unilateral ureteral injury. J Urol 189(3):960-965

7. Joshi HB, Obadeyi OO, Rao PN (1999) A comparative analysis of nephrostomy, JJ stent and urgent in situ extracorporeal shock wave lithotripsy for obstructing ureteric stones. BJU Int 84(3):264-269

8. Picozzi SC, Ricci C, Gaeta M et al (2012) Urgent shock wave lithotripsy as first-line treatment for ureteral stones: a meta-analysis of 570 patients. Urol Res 40(6):725-731 
9. Torricelli FC, Marchini GS, Pedro RN, Monga M (2016) Ureteroscopy for management of stone disease: an up to date on surgical technique and disposable devices. Minerva Urol Nefrol 68(6):516-526

10. Osorio L, Lima E, Soares J et al (2007) Emergency ureteroscopic management of ureteral stones: why not? Urology 69(1):27-31

11. Picozzi SC, Ricci C, Gaeta M et al (2012) Urgent ureteroscopy as first-line treatment for ureteral stones: a meta-analysis of 681 patients. Urol Res 40(5):581-586

12. Blackwell RH, Barton GJ, Kothari AN et al (2016) Early intervention during acute stone admissions: revealing "the weekend effect" in urological practice. J Urol 196(1):124-130

13. Wells GA, Shea B, O'Connell D et al (2017) The Newcastle Ottawa 1 scale (NOS) for assessing the quality of nonrandomized studies in meta-analyses. http://www.ohri.ca/programs/ clinical_epidemiology/oxford.asp

14. Jadad AR, Moore RA, Carroll D et al (1996) Assessing the quality of reports of randomized clinical trials: is blinding necessary? Control Clin Trials 17:1-12

15. Hozo SP, Djulbegovic B, Hozo I (2005) Estimating the mean and variance from the median, range, and the size of a sample. BMC Med Res Methodol 5:13

16. Youn JH, Kim SS, Yu JH, Sung LH, Noh CH, Chung JY (2012) Efficacy and safety of emergency ureteroscopic management of ureteral calculi. Korean J Urol 53(9):632-635

17. Guercio S, Ambu A, Mangione F et al (2011) Randomized prospective trial comparing immediate versus delayed ureteroscopy for patients with ureteral calculi and normal renal function who present to the emergency department. J Endourol 25:1137-1141

18. Sarica K, Tanriverdi O, Aydin M et al (2011) Emergency ureteroscopic removal of ureteral calculi after first colic attack: is there any advantage? Urology 78:516-552

19. Matani YS, Al-Ghazo MA, Al-Azab RS, Hani OB, Ghalayini IF, Hani IB (2013) Emergency versus elective ureteroscopic treatment of ureteral stones. Can Urol Assoc J 7(7-8):E470-E474

20. Kravchick S, Bunkin I, Stepnov E, Peled R, Agulansky L, Cytron S (2005) Emergency extracorporeal shockwave lithotripsy for acute renal colic caused by upper urinary-tract stones. J Endourol 19(1): $1-4$

21. Tombal B, Mawlawi H, Feyaerts A, Wese FX, Opsomer R, Van Cangh PJ (2005) Prospective randomized evaluation of emergency extracorporeal shock wave lithotripsy (ESWL) on the short-time outcome of symptomatic ureteral stones. Eur Urol 47(6):855-859

22. Kumar A, Mohanty NK, Jain M, Prakash S, Arora RP (2010) A prospective randomized comparison between early $(<48 \mathrm{~h}$ of onset of colicky pain) versus delayed shockwave lithotripsy for symptomatic upper ureteral calculi: a single center experience. J Endourol 24(12):2059-2066

23. Uguz S, Senkul T, Soydan H, Ates F et al (2012) Immediate or delayed SWL in ureteric stones: a prospective and randomized study. Urol Res 40(6):739-744
24. Choi HJ, Jung JH, Bae J, Cho MC, Lee HW, Lee KS (2012) Usefulness of early extracorporeal shock wave lithotripsy in colic patients with ureteral stones. Korean J Urol 53(12):853-859

25. Dindo D, Demartines N, Clavien PA (2004) Classification of surgical complications: a new proposal with evaluation in a cohort of 6336 patients and results of a survey. Ann Surg 240:205-213

26. Deliveliotis C, Chrisofos M, Albanis S et al (2003) Management and follow-up of impacted ureteral stones. Urol Int 70:269-272

27. Mueller SC, Wilbert D, Thueroff JW, Alken P (1986) Extracorporeal shock wave lithotripsy of ureteral stones: clinical experience and experimental findings. J Urol 135:831-834

28. Cummings JM, Boullier JA, Izenberg SD, Kitchens DM, Kothandapani RV (2000) Prediction of spontaneous ureteral calculous passage by an artificial neural network. J Urol 164(2):326-328

29. Parr NJ, Pye SD, Ritchie AW, Tolley DA (1992) Mechanisms responsible for diminished fragmentation of ureteral calculi: an experimental and clinical study. J Urol 148(3 Pt 2):1079-1083

30. Al-Ghazo MA, Ghalayini IF, Al-Azab RS et al (2011) Emergency ureteroscopic lithotripsy in acute renal colic caused by ureteral calculi: a retrospective study. Urol Res 39(6):497-501

31. Zargar-Shoshtari K, Anderson W, Rice M (2015) Role of emergency ureteroscopy in the management of ureteric stones: analysis of 394 cases. BJU Int 115(6):946-950

32. Ouzaid I, Al-qahtani S, Dominique S et al (2012) A 970 Hounsfield units (HU) threshold of kidney stone density on non-contrast computed tomography (NCCT) improves patients' selection for extracorporeal shockwave lithotripsy (ESWL): evidence from a prospective study. BJU Int 110(11 Pt B):E438-E442

33. Panesar SS, Bhandari M, Darzi A, Athanasiou T (2009) Metaanalysis: a practical decision making tool for surgeons. Int J Surg 7(4):291-296

34. Zwahlen M, Renehan A, Egger M (2008) Meta-analysis in medical research: potentials and limitations. Urol Oncol 26(3):320-329

35. De Sio M, Autorino R, Quarto G et al (2007) A new transportable shock-wave lithotripsy machine for managing urinary stones: a single-centre experience with a dual-focus lithotripter. BJU Int 100(5):1137-1141

36. Rassweiler JJ, Knoll T, Köhrmann KU et al (2011) Shock wave technology and application: an update. Eur Urol 59(5):784-796

37. Hollingsworth JM, Norton EC, Kaufman SR, Smith RM, Wolf JS Jr, Hollenbeck BK (2013) Medical expulsive therapy versus early endoscopic stone removal for acute renal colic: an instrumental variable analysis. J Urol 190(3):882-887

38. Dauw CA, Kaufman SR, Hollenbeck BK et al (2014) Expulsive therapy versus early endoscopic stone removal in patients with acute renal colic: a comparison of indirect costs. J Urol 191(3):673-677

39. Monga M (2014) When, for how long and in whom should medical expulsive therapy be used? J Urol 191(3):581 